\title{
Alternation as a function of drive level and visual complexity
}

J. GARRY BAKER AND ROBERT E. FRANKEN

UNIVERSITY OF CALGARY
The experiment provides evidence that rats will choose visual complexity over food in an altemation type task. The experiment generalizes previous findings that rats will select spatial stimulus complexity (i. e., a patterned stimulus) over food by showing that $S$ s will also select temporal stimulus complexity over food. The failure to obtain a decrease in response to temporal complexity over days, either as a result of rewarded trials or repetition, is attributed to the method of pacing temporal stimulus complexity.

Sackett, Keith-Lee, \& Treat (1963) and May, Beauchamp, \& Pollock (1965) have shown that rats will choose a visually complex stimulus over food in a $\mathrm{T}$ maze. One problem with both studies is the failure to adequately familiarize Ss with the presence of food reward prior to the introduction of the complex stimulus. For example, on the first experimental trial representing a choice between the complex stimulus and food, Ss have no knowledge of the presence of food at the end of the arms of the $T$ maze. If one of the arms is more complex, behavior at the choice point may be governed by preference for the more complex stimulus. The $\mathrm{S}$ is confronted with the same situation on subsequent trials, and unless $S$ approaches the simple stimulus and receives food reward, no knowledge about food is acquired. If the more complex stimulus is reinforcing, the choice behavior on any given trial may reflect in part the reinforcing effects of the complex stimulus on previous trials. The problem is to introduce a visually complex stimulus after $S$ has had the opportunity to learn that a food incentive is actually present in one arm of the maze. In the present study, this is achieved in an alternation type situation where the complex stimulus is introduced each day for four days after the two daily trials with food. This procedure insures that Ss have become familiarized with the presence of food without the confounding effects due to the presence of the differentially complex stimuli on food trials.

It has been demonstrated that alternation behavior is maintained following a number of food rewarded trials in one alternative of a $T$ maze (e.g., Fowler, Blond, \& Dember, 1959) and increases following forced trials (e.g., Dember \& Fowler, 1959). One explanation is that Ss are merely avoiding the repetition of a response to spatial and odor cues encountered in selecting or entering and alternative (Douglas, 1966). In one of the experimental conditions of the present experiment these cues are neutralized by giving Ss equal experience with the alternatives, prior to making a visual change.

\section{Method}

The Ss were 45 male and 45 female naive blackhooded rats about 90 to 120 days of age and supplied from the National Laboratory Supply in Edmonton, Alberta. The Ss were randomly assigned to one of the nine experimental groups so that each condition had five male and five female Ss.

The apparatus was a simple $T$ maze of the following dimensions: height, 8 in.; width, 6 in.; length of stem, 28 in. (the first 8 in. of the stem were separated from the rest of the stem by a clear plastic door in order to form a start box); each arm, 18 in. with the last 8 in. of the arm also $8 \mathrm{in}$. wide so as to form a distinguishable goal box. Clear plastic doors at the union of the arms and the stem were employed to retain Ss in one of the goal arms or to force $S$ to enter one arm on certain forced choice trials. Interchangeable goal box walls made it possible to change the stimulus patterns between trials. The entire maze, excluding the goal box walls, was painted flat gray. The various interchangeable goal box walls were lined with one of five stimulus cards made from black tape and white cardboard: (1) black, (2) white, (3) 2 in. wide black and white horizontal stripes, (4) 1 in. wide black and white vertical stripes, and (5) 1 in. black and white checkerboard squares. All Ss were placed on appropriate deprivation schedules two weeks prior to the experimental trials and handled in groups of four for $10 \mathrm{~min}$ a day. There were three levels of deprivation for each of the three experimental conditions. Deprivation schedules used were $0 \mathrm{~h}, 4 \mathrm{~h}$, and $22 \mathrm{~h}$. The three experimental conditions were as follows:

(a) Repetition-change group. These Ss were given a free-choice trial with both goal boxes having the white stimulus cards lining the walls. On Trial 2 Ss were forced to the same side they had entered on Trial 1 by lowering the retracing door for the non-entered arm. Both trials were rewarded. Between Trials 2 and 3 the walls of the non-entered goal box were changed to black and on Trial $3 \mathrm{~S}$ was allowed a freechoice. The change between Trials 2 and 3 constitutes a temporal stimulus change.

(b) Repetition-no change group. Trials 1 and 2 were the same as in the preceding group; however, no change was made in the non-entered goal box. Again Ss were given a free-choice trial on Trial 3 with no food reward available.

(c) Alternation-change group. Trial 1 was the same as the preceding two groups. Between Trials 1 and 2 the retracing door to the entered arm was lowered. The $S$ was forced to enter the previously non-entered 
Table 1

Stimulus Condition $\frac{\text { Percent alternation over } 40 \text { test trials }}{0 \text { hour } 4 \text { hour } 22 \text { hour }}$

Repetition-chonge $\quad 35 \% ; p<.00173 \% ; p<.00478 \% ; p<.001$

Repetition no-change $60 \% ; \mathrm{p}=.15685 \% ; \mathrm{p}<.00160 \% ; \mathrm{p}=.156$

Alternation-change $\quad 53 \% ; p=.47653 \% ; p=.476 \quad 70 \% ; p<.009$

$p$ values for one-tailed test using $z$ approximation to the binomial

arm. Between Trials 2 and 3 the goal box walls of the non-entered arm (Trial 1) were changed to black for half the Ss and the goal box walls of the entered arm (Trial 1) for the remaining Ss. On Trial $3 \mathrm{~S}$ was allowed a free choice.

The procedure was the same on the three subsequent days except that the stimuli were different. On Trials 1 and 2 of Day 2, black walls were used, while the horizontal striped walls were used for the change condition. On Day 3, the horizontal striped walls were used on Trials 1 and 2 while the vertical striped walls were used for the change condition. On Day 4, the vertical striped walls were used on Trials 1 and 2 while the checkerboard patterned walls were used in the change condition. This procedure insured that Ss could not associate the cue value of any stimulus (e.g., horizontal stripes) with the change value (e.g., difference between a white stimulus and a horizontal striped stimulus on successive trials).

The Ss were run over three successive weeks, one drive level group per week. On the two days prior to the experiment each $\mathrm{S}$ was given $5 \mathrm{~min}$ adaptation in the stem of the maze with retracing doors present and gray goal boxes.

Results

The data recorded were the proportion of alternationnonalternation responses for each group of $10 \mathrm{Ss}$. These data were transformed by the arc sine transformation. There was a significant effect due to stimulus conditions ( $F=19.02$, $\mathrm{df}=2 / 12, \mathrm{p}<.005)$ and stimulus conditions by drive level $(\mathrm{F}=10.49$, $\mathrm{df}=4 / 12, \mathrm{p}<.005)$. There was no main effect or interaction effect associated with days; consequently the data were pooled over days. Table 1 presents percent alternation over 40 pooled test trials and corresponding probability values as evaluated by the $\mathrm{z}$ approximation to the binomial. The data may be summarized as follows:

(a) The Ss that were forced to repeat their responses and provided with a change on Trial 3 all responded to the more complex or changed stimulus on Trial 3. There was no effect due to deprivation level or number of rewarded trials.

(b) The Ss that were forced to repeat their responses but not provided with a change on Trial 3 showed an interaction effect with deprivation level. The $4 \mathrm{~h}$ deprived Ss alternated their response on Trial 3; however, the 0 and $22 \mathrm{~h}$ deprived groups did not.

(c) The Ss that were forced to alternate on Trial 2 and provided with a change on Trial 3 also showed an interaction effect with deprivation level. Only the $22 \mathrm{~h}$ deprived Ss approached the more complex or changed stimulus.

\section{Discussion}

The failure to find an effect due to days for any of the drive-stimulus conditions indicates that either food reward had no effect or its maximal effect occurred on the first two trials of Day 1. While food reward appears to have little or no effect on changing the amount of alternation, level of deprivation did appear to have a complex effect upon alternation. The explanation of this interaction is offered in another paper (Franken \& Baker, 1967) and, consequently, will not be discussed further.

For the most part, the results support a stimulus change explanation, such as that proposed by Dember \& Earl (1957). Change seems to be sufficiently motivating in the present task to override the effects of food reward. The data indicate that the explanation offered by Douglas (1966) is limited to those situations in which only two trials are used and no visual changes are manipulated.

The data generalize the findings of Sackett et al and May et al by demonstrating that it is not a unique function of the complexity value of a given stimulus, but a function of the change in the measure of complexity between trials that is motivating. The failure to find any decrease in the stimulus change effect over days may indicate that proper pacing of stimulus change can provide a powerful source of motivation similar to that observed under food deprivation and reward conditions.

\section{References}

Dember, W. N., \& Earl, R. W. Analysis of exploratory, manipulatory and curiosity behaviors. Psychol. Rev., 1957, 64, 91-96.

Dember, W. N., \& Fowler, H. Spontaneous alternation after free and forced trials. Canad. J. Psychol., 1959, 13, 151-154.

Douglas, R. J. Cues for spontaneous alternation. J. comp. physiol. Psychol., 1966, 62, 171-183.

Franken, R. E., \& Baker, J. G. Drive levels and cue utilization in spontaneous alternation. Psychon. Sci., 1967, 8,

Fowler, H., Blond, J., \& Dember, W. N. Alternation behavior and learning: The influence of reinforcement magnitude, number, and contingency. J. comp. physiol. Psychol, 1959, 52, 609-614.

May, R. B., Beauchamp, K. L., \& Pollock, S. Visual stimulus complexity and food versus food alone as reward for rats. Psychon. Sci., 1965, 3, 403-404.

Sackett, G. P., Keith-Lee, P., \& Treat, R. Food versus perceptual complexity as rewards for rats previously subjected to sensory deprivation. Science, 1963, 141, 518-520. 